\title{
Despliegue de los efectos de la Ley $5 / 2010$ de 11 de junio de autonomía local de Andalucía a través de la Ley $9 / 2014$ de 31 de Diciembre del Consejo Andaluz de Concertación Local
}

\author{
Francisco Manuel Silva Ardanuy \\ Doctor en Derechos \\ Dpto. Derecho Público \\ Universidad Pablo de Olavide
}

SUMARIO: I. INTRODUCGIÓN.-II. GONTENIDO Y ALCANCE.PROCESO DE DEBATE PARLAMENTARIO.-DEBATE FINAL DEL PROYECTO DE LEY 9-14/PL-0000005 DEL CONSEJO ANDALUZ DE GONGERTAGIÓN LOGAL EN LA SESIÓN PLENARIA DEL PARLAMENTO DE ANDALUCÍA DE 22 DE DIGIEMBRE DE 2014.- BIBLIOGRAFÍA Y FUENTES.

RESUMEN: El 22 de Diciembre de 2014 el Parlamento de Andalucía aprobaba la Ley 9/2014 del Consejo Andaluz de Concertación Local . Se daba cumplimiento a los contenidos expresados en el artículo 57 de la Ley 5/2010 de 11 de junio de autonomía local de Andalucía sobre la base de lo expresado en la Ley 20/2007, de 17 de diciembre, que creaba el Consejo Andaluz de Concertación Local en cumplimiento de la previsión contenida en el artículo 95 del Estatuto de Autonomía para Andalucía. La ley aprobada se anuda con el derecho comunitario a través de la Carta Europea de la Autonomía Local, tal como indica en su artículo 4.6 En este sentido, la Ley 7/1985, de 2 de abril, Reguladora de las Bases del Régimen Local, establece en su artículo 55 y 58 el marco de relaciones entre Administración Autonómica y Gobiernos locales. Se culmina así el proceso de elaboración de una norma que viene a perfeccionar e institucionalizar las modalidades de participación y decisión de las entidades locales en las cuestiones de índole legislativa que versen sobre temas que les incumban directamente.

PALABRAS CLAVE: Autonomía Local, concertación, Consejo Andaluz de Gobiernos locales, competencias, Estatuto de autonomía, régimen local. 
ABSTRACT: On December 22, 2014 the Andalusian Parliament approved the law 9/2014 of the Andalusian Council of Local consultation. It was fulfillment of the contents expressed in article 57 of the law 5/2010 of 11 June of local autonomy of Andalusia on the basis of the law 20/2007, of December 17, that created the Andalusian Council of Local consult in accordance with the provision contained in article 95 of the Statute of autonomy for Andalusia. The law passed is knotted with the Community law through the European Charter of Local self-government, indicated in its article 4.6 in this sense, law 7/1985, of 2 April, regulating the Bases of the regime Local, establishes in its article 55 and 58 establishes the framework of relations between the regional administration and local governments. Thus completes the process of elaboration of a standard that comes to improve and institutionalize the modalities of participation and decision of local authorities on the legislative issues related to topics that incumbent on them directly.

KEY WORDS: Local autonomy, consultation, Andalusian Council of local governments, competencies, Statute of autonomy, local government.

\section{I.- INTRODUGCIÓN}

Tras el acuerdo del Consejo de Gobierno de la Junta de Andalucía el 8 de julio de 2014, el 22 de octubre de 2014 se daba inicio a la tramitación parlamentaria del proyecto de Ley del Consejo Andaluz de Concertación Local ${ }^{1}$ que sería definitivamente aprobado el 22 de Diciembre del mismo año.

${ }^{1}$ Como fases precedentes, el Anteproyecto de la citada ley fue sometido a debate en las sesiones de la Comisión General de Viceconsejeros de los días 28 de julio y 2 de octubre de 2013. El 9 de octubre de 2013, remitiendo el texto del Anteproyecto para su aprobación al Consejo de Gobierno el 9 de octubre de 2013. En su sesión del 15 de octubre de 2013, el Consejo de Gobierno autoriza la tramitación del Anteproyecto.

Una vez tramitada, en aprobación como Proyecto de Ley, la Comisión General de Viceconsejeros acuerda en su sesión del 14 de mayo de 2014 someter el mismo al Dictamen del Consejo Consultivo de Andalucía que emitió su dictamen el 24 de junio de 2014. Tras la recepción e incorporación de las consideraciones contenidas en el dictamen del Consejo Consultivo, la Comisión general de Viceconsejeros en su sesión del 2 de julio de 2014 elevó el texto resultante al consejo de Gobierno que en se sesión de 9 de julio de 2014 aprueba el texto como proyecto de Ley.

El 15 de julio de 2014 tiene entrada en el registro del parlamento el proyecto de Ley recibiendo calificación favorable y admisión a trámite por parte de la mesa del parlamento de Andalucía el 3 de septiembre de 2014, siendo publicado en BOPA el 8 de septiembre de 2014. Finalizado el plazo de presentación de enmiendas a la totalidad, el 25 de septiembre y no habiéndose registrado enmiendas a la totalidad se procede a su debate en términos de totalidad en la sesión plenaria de 22 de octubre. Tras la comparecencia de los agentes sociales el 18 de Noviembre de 2014 se procede a la calificación de las enmiendas al articulado formulada por los grupos parlamentarios en la me- 
El Estatuto de Autonomía para Andalucía presta especial atención a las exigencias propias de esta distribución territorial del poder, disponiendo en su artículo 89.2 que la Administración de la Comunidad Autónoma y las Administraciones Locales ajustarán sus relaciones a los principios de información mutua, coordinación, colaboración y respeto a los ámbitos competenciales correspondientes determinados en el Estatuto, en la legislación básica del Estado y en la normativa autonómica de desarrollo, con plena observancia de la garantía institucional de la autonomía local reconocida por la Constitución y por la Carta Europea de la Autonomía Local².

La Ley del Consejo Andaluz de Concertación Local se plantea para su aprobación al amparo de las competencias exclusivas de esta Comunidad Autónoma sobre el régimen local, respetando el artículo 149.1.18 de la Constitución y el principio de autonomía local, así como sobre la estructura y regulación de los órganos administrativos públicos de Andalucía, en virtud de los artículos 60.1 y 47.1.1ª , respectivamente, del Estatuto de Autonomía para Andalucía ${ }^{3}$.

El Consejo Andaluz de Concertación Local ya había tenido una regulación precedente, en la Ley 20/2007, de 17 de Diciembre que reguló la naturaleza de un órgano mixto, de carácter paritario, que eleva a principio fundamental de su funcionamiento el diálogo y la colaboración institucional, y que debe ser consultado en el trámite parlamentario de disposiciones legislativas y planes que afecten a las corporaciones locales.

sa de la comisión de Administración Local y Relaciones Institucionales de 3 de diciembre de 2014. El dictamen de la ponencia fue emitido el 4 de diciembre de 2014 siendo sometido a consideración de los grupos en la comisión parlamentaria del 10 de diciembre de 2014. Tras la finalización del plazo para la comunicación de los votos particulares y mantenimiento de enmiendas el 13 de diciembre de diciembre de 2014 y su inclusión en el orden del día del pleno del parlamento el 17 de diciembre, la Ley del Consejo Andaluz de Concertación local queda definitivamente aprobada el 22 de diciembre de 2014 y publicada como Ley 9/2014 de 30 de Diciembre en el BOJA número 255 de 31 de diciembre.

2 BARNÉS VÁZQUEZ, J.: "Descentralización y desconcentración en Andalucía” en DA, 214, 1988, pag.93 y ss. CRUZ VILLALÓN, P.: "La reforma del Estado de las autonomías" en Revista d'Estudis Autonòmics i Federals, num. 2, 2006, págs. 90-91.GÓMEZ MONTORO, A. : "La garantía constitucional de autonomía local" en Repertorio Aranzadi de Furisprudencia Constitucional, num. 1, 1999, pág. 17 y ss.LÓPEZ GUERRA, L.: "La función constitucional y el contenido del Estatuto de Autónomía" en Estudios sobre la reforma del Estatuto, Institut d'Estudis Autonomics i Federals, 2004, pag.11. LÓPEZ-MEDEL BÁSCONES, J.: "Autonomía y descentralización local”, El Consultor de los Ayuntamientos y los fuzgados, Madrid, 2003.

${ }^{3}$ GALÁN GALÁN, A.: "Naturaleza de la Ley de régimen local de Andalucía y su relación con las leyes autonómicas sectoriales" en Anuario del Gobierno Local, Institut de Dret Public, Barcelona, 2009.VELASGO CABALLERO, F.: "Autonomía local en los nuevos Estatutos de autonomía". Ponencia en las jornadas Reforma del Gobierno Local en Andalucía, CEMCI-Fundación Democracia y Gobierno Local. Granada, 18 y 19 de enero de 2010. 
La Ley 20/2007, de 17 de diciembre, creaba el Consejo Andaluz de Concertación Local en cumplimiento de la previsión contenida en el artículo 95 del Estatuto de Autonomía para Andalucía que establece que "una ley de la Comunidad Autónoma regulará la creación, composición y funciones de un órgano mixto con representación de la Junta de Andalucía y de los Ayuntamientos andaluces, que funcionará como ámbito permanente de diálogo y colaboración institucional, y será consultado en la tramitación parlamentaria de las disposiciones legislativas y planes que afecten de forma especifica a las Corporaciones locales".

Dicha ley se anuda con el derecho comunitario a través de la Carta Europea de la Autonomía Local, que indica en su artículo 4.6 que las Entidades Locales deben ser consultadas, en la medida de lo posible, a su debido tiempo y de forma apropiada, a lo largo de los procesos de planificación y de decisión para todas las cuestiones que les afecten directamente. Las relaciones interadministrativas adquieren, por tanto, un especial significado, coexistiendo en la actualidad tres ámbitos de decisión, el estatal, el autonómico y el local, sin perjuicio de las competencias de las instituciones comunitarias ${ }^{4}$.

En este sentido, la Ley 7/1985, de 2 de abril, Reguladora de las Bases del Régimen Local, establece en su artículo 55 los principios que deben regir las relaciones recíprocas entre las Administraciones del Estado y de las Comunidades Autónomas de un lado, y las Entidades Locales de otro, para la efectividad de la coordinación y la eficacia administrativas ${ }^{5}$. En su artículo 58, esta Ley faculta a las Comunidades Autónomas para crear, mediante ley, órganos de colaboración con las Entidades Locales. Estos órganos serán únicamente deliberantes o consultivos, y podrán tener ámbito autonómico o provincial y carácter general o sectorial.

En el uso de la competencia que sobre régimen local el artículo 13.3 del anterior Estatuto de Autonomía para Andalucía atribuía a la Comunidad Autónoma de Andalucía, la participación de los entes locales andaluces en los asuntos de competencia autonómica que afectaren a sus respectivos intereses y, por lo tanto, al ámbito de au-

\footnotetext{
${ }^{4}$ CAAMAÑO DOMÍNGUEZ, F. (Coord.): La autonomía de los entes locales en positivo. La carta Europea de la Autonomía Local como fundamento de la suficiencia financiera, Fundación democracia y Gobierno Local, Madrid, 2003.GARCÍA FERNÁNDEZ, J. : "Derecho constitucional y entidades locales. Sistema de fuentes y autonomía como fundamentos constitucionales básicos de la autonomía local", en Parlamento y Constitución, num, 6, 2002, pág. 205 y ss. ORTEGA ÁLVAREZ, L. : "La Carta Europea de la Autonomía Local y el ordenamiento español" en Revista de Estudios de la Administración Local y Autonómica, num. 259, 1993, pág. 475 y ss. RODRÍGUEZ ÁLVAREZ, J.M. : "La Carta Europea de la Autonomía Local. Su trascendencia y significación en el ordenamiento jurídico español” en Actualidad administrativa, num. 42, Noviembre de 1997, pág. 911 y ss.

${ }^{5}$ ESTEVE PARDO, J. . "Garantía constitucional y la función constitucional en las bases de régimen local” en Revista de Estudios Derecho Constitucional, num. 31, 1991, pág.125 y ss.
} 
tonomía que la Constitución les reconoce, se canalizó mediante la creación del Consejo Andaluz de Provincias y el Consejo Andaluz de Municipios. Estos órganos colegiados tienen importantes funciones encomendadas, en cuanto son cauce de participación efectiva de las Provincias y Municipios andaluces en asuntos de su interés, cuya decisión corresponda a la Administración autonómica ${ }^{6}$.

\section{II.- GONTENIDO Y ALGANCE}

La voluntad de cumplimiento con los principios de descentralización y desconcentración que establece el texto constitucional y el propio Estatuto de Autonomía, llevó en el año 2010 a la aprobación de la Ley 5/2010, de 11 de junio, de Autonomía Local de Andalucía, que en su artículo 57 creaba el Consejo Andaluz de Gobiernos Locales como "órgano de representación de los municipios y las provincias ante las instituciones de la Junta de Andalucía con la finalidad de garantizar el respeto a las competencias locales $" 7$.

Ley 5/2010, de 11 de junio, de Autonomía Local de Andalucía, creó en su artículo 57 el Consejo Andaluz de Gobiernos Locales como "órgano de representación de los municipios y las provincias ante las instituciones de la Junta de Andalucía con la finalidad de garantizar el respeto a las competencias locales" ${ }^{2}$.

${ }^{6}$ ARAGÓN REYES, M.: "El tratamiento constitucional de la autonomía local” en Organización territorial del Estado, Instituto de Estudios Fiscales, Madrid, 1985, págs. 463 y ss. BARNÉS VÁZQUEZ, J.: "Un Estado de autonomía y una Constitución del Siglo XX" en Revista de Administración Pública, num, 173, Madrid, Mayo-Agosto, 2007, pág. 293-315. FONT i LLOVET, T.: "El Gobierno local en la reforma del Estado de las Autonomías" en Anuario del Gobierno Local 2004, 2005, pág.13-40. Véase del mismo autor "El régimen local en la reforma de los Estatutos de autonomía" en El régimen local en la reforma de los estatutos de autonomía, Centro de Estudios Políticos y Constitucionales, Madrid, 2006.

${ }^{7}$ VILLALTA REIXACH, M.: "nuevas formas de participación de los entes locales; el Consejo de Gobiernos Locales" en Revista d'Estudis Autonòmics i Federals, num. 2, 2006, págs. 225-264."El Consejo de Gobiernos locales. La nueva participación de los entes locales en las CC.AA.", Madrid, IUSTEL, 2007.

${ }^{8}$ AJA, Elíseo: "Configuración constitucional de la autonomía municipal", en Informe sobre el G0bierno Local, MAP, Madrid, 1992, págs. 41 y ss. FANLO LORAS, A. . Fundamentos constitucionales de la autonomía local, Centro de Estudios Constitucionales, Madrid, 1990.GARCÍA ROCA, J. : "El concepto actual de autonomía local según el bloque de la constitucionalidad", en Revista de estudios de la Administración Local y Autonómica, 282, 2000, pág. 23 y ss. GÓMEZ MONTORO, A. : "La garantía constitucional de autonomía local" en Repertorio Aranzadi de Jurisprudencia Constitucional, num. 1, 1999, pág. 17 y ss. 
El Consejo Andaluz de Gobiernos Locales es una reivindicación del municipalismo cuya composición, en concordancia con la función representativa que desempeña, es exclusivamente local. Es por dicho motivo que la referida Ley 5/2010, de 11 de junio, le atribuye algunas de las funciones que venía desempeñando el Consejo Andaluz de Concertación Local, partiendo de la consideración de que el parecer del nivel de gobierno local, ante las perspectivas de actuación autonómica, debe conformarse de modo autónomo, sin interferencias de otros niveles de gobierno ${ }^{9}$.

Podemos definir por tanto el Consejo Andaluz de Concertación Local como órgano supremo de colaboración y concertación de la Junta de Andalucía y los Gobiernos Locales, es un órgano colegiado permanente, de carácter deliberante y consultivo de la Junta de Andalucía, que dispone de autonomía funcional para el cumplimiento de sus fines.

De este modo, y expresándolo en términos de Derecho positivo, las funciones del Consejo Andaluz de Concertación Local serán las siguientes:

1.- Ser consultado en la tramitación parlamentaria de las disposiciones legislativas y planes que afecten de forma específica a las entidades locales, de conformidad con lo dispuesto en el artículo 95 del Estatuto de Autonomía para Andalucía y en los términos que establezca el Reglamento del Parlamento de Andalucía.

2.- Informar los anteproyectos de ley, los proyectos de disposiciones generales y las propuestas de planes, cuando el órgano proponente rechace observaciones o reparos del Consejo Andaluz de Gobiernos Locales que expresamente se hayan realizado por resultar afectadas las competencias locales propias.

3.- En el marco de lo previsto en el artículo 93.1 del Estatuto de Autonomía para Andalucía, y en la sección $4^{\text {a }}$ del Capítulo II del Título I de la Ley 5/2010, de 11 de junio, formular propuestas al Consejo de Gobierno de la Junta de Andalucía, sobre la transferencia y delegación de competencias a las entidades locales.

4.- Resolver los problemas de interpretación y cumplimiento que puedan plantearse respecto del proceso de transferencia de competencias propias de la Comunidad Autónoma de Andalucía a los municipios, conforme a lo establecido en el artículo

${ }^{9}$ GARCí́A FERNÁNDEZ, J. : "La autonomía del Derecho Político municipal. Fundamentos dogmáticos en la Constitución Española" en Organización territorial del estado (Administración Local), Instituto de Estudios Fiscales, Madrid, 1985.ZAFRA VÍCTOR, M. : "Autonomía local. Un pilar en la articulación del Estado de las Autonomías" en Relaciones Institucionales entre CC.AA. y Gobiernos Locales, Sevilla, Instituto Andaluz de Administración Pública, 2008. 
17.3 de la Ley 5/2010, de 11 de junio, así como respecto de las delegaciones, transferencias o cualquier tipo de traslación competencial que pueda producirse entre la Comunidad Autónoma y las entidades locales, incluyendo la reversión de las mismas.

5.- Formular propuestas al órgano competente, relativas a objetivos, prioridades y financiación de las entidades locales, en orden a la realización de obras y a la gestión de servicios que concierten o les encomiende la Junta de Andalucía, de entre los que sean de la competencia específica de la Comunidad Autónoma.

6.- Emitir su parecer en los procedimientos de creación y supresión de municipios o de alteración de sus términos, de conformidad con lo dispuesto en el artículo 97.5 y en el artículo 98.4 de la Ley 5/2010, de 11 de junio.

7.- Emitir informe en los procedimientos de cambio de nombre y de capitalidad de los municipios, de acuerdo con lo establecido en el artículo 108.1 de la Ley 5/2010, de 11 de junio de autonomía Local de Andalucía

8.- Efectuar a la Consejería competente sobre régimen local, propuestas de colaboración con las provincias andaluzas en relación con las funciones de asistencia a los municipios que tienen atribuidas por la Ley 5/2010, de 11 de junio.

9.- Efectuar al órgano competente de la Junta de Andalucía propuestas de cooperación con los municipios y con las demás entidades locales de Andalucía para la consecución de los fines previstos en el artículo 60 de la Ley 5/2010, de 11 de junio, a través de las entidades e instrumentos para la cooperación territorial establecidos en el artículo 62 de la citada Ley.

10.- Recibir información de los acuerdos del Consejo de Gobierno de la Junta de Andalucía mediante los que se solicite del Consejo de Ministros la disolución de los órganos de las Corporaciones Locales, en los supuestos de gestión gravemente dañosa para los intereses generales.

Junto con el conjunto de funciones que demarcan las acciones posibles del Consejo Andaluz de Concertación Local se apareja un régimen de organización y funcionamiento que en virtud de lo establecido por el artículo 4.2 de la presente Ley determina que los acuerdos se adoptarán por consenso entre las representaciones de la Junta de Andalucía y de los Gobiernos Locales, excepto en el caso previsto en el artículo 3.1.d de esta Ley, en el que de no lograrse un consenso, el acuerdo se adoptará por mayoría de sus miembros y, de producirse empate decidirá la Presidencia con su voto de calidad. 
Se entenderá que se ha producido el consenso en caso de que emitan voto afirmativo la mayoría de los miembros presentes en cada una de las sesiones. En el supuesto de no alcanzarse un acuerdo por consenso, se harán constar las posturas discrepantes de cada una de las partes, tanto en el acta como, en su caso, en los informes, propuestas o acuerdos adoptados por el Consejo.

En los supuestos de informes a nuevos textos normativos, el Consejo de Concertación sólo intervendrá en caso de discrepancias entre el dictamen del Consejo Andaluz de Gobierno Locales y la Consejería que los promueva. Así, este órgano mixto Junta-Entidades locales intentará el acercamiento de posturas y evitará recurrir a los tribunales cada vez que surjan desacuerdos entre las dos administraciones.

En lo tocante a la composición del Consejo Andaluz de Concertación Local, la estructura será la siguiente:

1.- En representación de la Junta de Andalucía:

- La persona titular de la Consejería competente sobre régimen local.

- La persona titular de la Viceconsejería competente sobre régimen local.

- Siete (7) personas vocales designadas por el Consejo de Gobierno de la Junta de Andalucía entre personas titulares de órganos directivos con rango de Viceconsejería.

- La persona titular del órgano directivo competente sobre régimen local, con rango de Dirección General, o del órgano que tenga atribuida dicha competencia.

2.- En representación de los Gobiernos Locales:

- La persona titular de la Presidencia de la asociación de municipios y provincias de carácter autonómico de mayor implantación en Andalucía.

- Ocho personas vocales, cuya designación se realizará por el órgano competente de la citada asociación de municipios y provincias.

- La persona titular de la Secretaría General de la citada asociación de municipios y provincias.

3.- Asistirá a las reuniones del Pleno, con voz pero sin voto, una persona en representación de la asociación de las entidades de gestión descentralizada con mayor implantación en Andalucía, cuya designación se realizará por la citada asociación.

4.- Ejercerá la Secretaría, con voz pero sin voto, una persona funcionaria, adscrita a la Dirección General competente sobre régimen local, o al órgano que tenga 
atribuida dicha competencia, que desempeñe, al menos, un puesto de jefatura de servicio, designada por su titular.

5.-Cuando la naturaleza de los asuntos a tratar así lo requiera, las personas titulares de las vocalías podrán asistir, al Pleno o a la Comisión Permanente, acompañadas de otras que no posean esa condición, debidamente autorizadas por la Presidencia, y podrán ser convocadas a las reuniones del Consejo otras personas representantes de la Junta de Andalucía, o de los Gobiernos Locales, a propuesta y por designación de la parte respectiva.

Junto con la estructura del Plenario existirá una Comisión Permanente para elevar aquellas propuestas de informe o pronunciamiento previstos en las funciones que corresponden al Consejo de Concertación Local.

El Consejo Andaluz de Concertación Local establecerá un régimen de sesiones que garantice al menos una reunión anual en sesión ordinaria con un orden del día previamente establecido que estará a disposición de los miembros del Consejo Andaluz de Concertación Local con una antelación mínima de cinco días. La actividad del Consejo andaluz de Concertación Local se ha materializado en la siguientes reuniones de Pleno y Comisión permanente:

\begin{tabular}{|l|c|c|}
\hline & Reuniones del Pleno & Reuniones Comisión Permanente \\
\hline 2008 & 1 & 7 \\
\hline 2009 & 2 & 27 \\
\hline 2010 & 1 & 29 \\
\hline 2011 & 0 & 49 \\
\hline 2012 & 0 & 29 \\
\hline 2013 & 1 & 37 \\
\hline 2014 & 3 & 37 \\
\hline TOTAL & 8 & 215 \\
\hline
\end{tabular}

Bajo las anteriores premisas, la Ley 5/2010, de 11 de junio, define el Consejo Andaluz de Concertación Local, en su artículo 85, como el órgano supremo de colaboración entre la Comunidad Autónoma y los Gobiernos Locales, en consonancia con 
el artículo 95 del Estatuto de Autonomía para Andalucía que lo instrumenta como ámbito permanente de diálogo y colaboración institucional, sustentando en dicha función colaborativa su fuerza diferencial, dentro del esquema orgánico que inaugura; de forma que la composición exclusivamente local del Consejo Andaluz de Gobiernos Locales hace efectivo el derecho de representación y participación de las entidades locales en las decisiones autonómicas, mientras que la composición mixta del Consejo de Concertación Local responde a su objetivo de instrumentar el diálogo permanente, la concertación y la colaboración entre ambos niveles de gobierno autonómico y local. La importancia del Consejo Andaluz de Concertación Local, como órgano en que se articulan las relaciones institucionales de las entidades locales con la Junta de Andalucía con el objetivo de alcanzar elevados niveles de consenso y colaboración que redunden a favor del conjunto de la ciudadanía está implícita en la esencia del Estado descentralizado, al ser las técnicas de cooperación y colaboración consustanciales a la estructura del Estado de las Autonomías ${ }^{10}$.

El significado mismo de la autonomía de cada uno de los entes jurídico-políticos que constituyen ambos niveles de gobierno, así como el deber de las Administraciones Públicas de actuar de acuerdo con los principios de eficacia y de cooperación activa, requiere facilitar la interlocución de ambos niveles de gobierno ante los importantes objetivos que les marca el Estatuto de Autonomía. El Consejo Andaluz de Concertación Local responde, por tanto, a la necesidad de buscar instrumentos de cooperación eficaces para el logro de las finalidades perseguidas ${ }^{11}$.

De este modo se adecuan las funciones del Consejo Andaluz de Concertación Local a su naturaleza de órgano de diálogo y colaboración institucional, teniendo en cuenta las que la Ley de Autonomía Local de Andalucía atribuye al Consejo Andaluz de Gobiernos Locales. Asimismo se destaca el régimen de adopción de sus acuerdos por consenso entre las representaciones de la Junta de Andalucía y de los Go-

\footnotetext{
${ }^{10}$ MEDINA ALCOZ, L. : La participación de los entes locales en la elaboración de normas autonómicas y locales, Madrid, INAP, 2009.MEDINA GUERRERO, M. : "Hacia una participación eficaz de los entes locales en la toma de decisiones de la Comunidad Autónoma, ¿Del Consejo andaluz de Concertación Local al Consejo de Gobiernos Locales? Revista CEMCI. Num. 8, Julio- septiembre 2010, pag. 1-12."Crónica parlamentaria. El debate final de la Ley de Autonomía Local en Andalucía" en Revista Andaluza de Administración Pública, num. 76, 2010, págs. 333-345.ORTÍZ MONTORO, R.J. : "Comentarios al proyecto de Ley de Autonomía Local de Andalucía de 2009" en El Consultor de los Ayuntamientos y los fuzgados, num. 5, quincena 15-29 de marzo, 2009, pág. 713.

11 TOSCANO GIL, F.; VILLALTA REIXACH, M. : "El consejo Andaluz de Concertación Local; una oportunidad perdida para la autonomía local en Andalucía" en Revista Andaluza de Administración Pública. Num. 70, 2008, pág.97-130.
} 
biernos Locales, eliminando el carácter dirimente del voto de la Presidencia, y el reforzamiento de la Comisión Permanente del Consejo, incrementando el número de sus miembros y elevando el rango de su Presidencia. No obstante lo anterior, se establece un régimen específico para la adopción de acuerdos en el supuesto previsto en el artículo 17.3 de la Ley 5/2010, de 11 de junio. Todo lo expuesto requiere la aprobación de una nueva ley del Consejo Andaluz de Concertación Local, para adecuar sus funciones, organización y funcionamiento al marco normativo actual y a la propia naturaleza del órgano, así como a las necesidades que se han puesto de manifiesto durante la vigencia de la Ley que lo crea ${ }^{12}$.

La presente Ley deroga la Ley 20/2007, de 17 de diciembre, del Consejo Andaluz de Concertación Local. Asimismo deroga el apartado 2 del artículo 2 del Reglamento de Funcionamiento del Consejo Andaluz de Gobiernos Locales, aprobado mediante Decreto 263/2011, de 2 de agosto, de manera que incorpora a las funciones del Consejo Andaluz de Gobiernos Locales el informar las disposiciones que desarrollen planes o disposiciones de carácter general aprobadas por el Consejo de Gobierno, para posibilitar el conocimiento del punto de vista local en la elaboración de esas disposiciones y en sintonía con las funciones al respecto atribuidas al Consejo Andaluz de Concertación Local.

\section{III.- PROCESO DE DEBATE PARLAMENTARIO.}

A partir del pleno del parlamento de Andalucía del 22 de octubre se dieron dos iniciativas parlamentarias en torno al Anteproyecto de ley del Consejo Andaluz de Concertación Local; por un lado, la emisión de una pregunta con ruego de respuesta oral en comisión por parte del G.P. PP-A relativa a la línea de organización del futuro Consejo de Concertación Local que fue atendida en la comisión de Administración Local del 30 de octubre de 2013. Por otro lado el G.P. PP-A presentó una Proposición No de Ley en la comisión de Administración Local del 5 de febrero de 2014 relativa a la reforma del Consejo Andaluz de Concertación Local que fue rechazada por ocho votos contrarios, siete votos a favor y ninguna abstención ${ }^{13}$.

12 PAREJO ALFONSO, J.: Garantía constitucional y autonomías locales, Instituto de estudios de Administración Local, Madrid, 1981.REQUEJO PAGÉS, J.L.: "Garantía de la autonomía local y Estatutos de Autonomía” en Anuario del Gobierno Local, 2006, pag. 55.RUIZ ROBLEDO, A.: El ordenamiento jurídico andaluz, Civitas, Madrid, 1991, pág. 174.

${ }^{13}$ DSPA num.226 de 5 de febrero de 2014. págs. 70-78. 
El 18 de Noviembre de 2014 se dio audiencia a los representantes de diferentes organizaciones sociales, agentes económicos y juristas a fin de conocer su posición sobre el proyecto de ley ${ }^{14}$.

El compareciente D. Manuel José Terol Becerra expone a los miembros de la comisión de Administración Local y Relaciones Institucionales que los asuntos de la Administración Local no deberían dejarse en manos de expertos, por a su juicio "no hay expertos" en este ámbito. La Constitución Española dice que las entidades locales gozarán de autonomía para la gestión de sus respectivos intereses, pero no dice más. Considera que debe romperse una lanza a favor de la autonomía local. Indica que el poder legislativo debe definir cuál y qué es la autonomía local. A su juicio, el artículo 95 establece con claridad la creación de un órgano para la concertación de los Gobiernos locales, en un momento en que las entidades locales son ya el órgano básico de coordinación entre la Administración Autonómica y la Administración Local.

Por su parte, D. José Francisco Salado Escaño, Alcalde del Excmo. Ayuntamiento de Rincón de la Victoria (Málaga) plantea la importancia de llegar a acuerdos en materia de Administración Local con principios de descentralización a fin de mejorar la vida de los ciudadanos. Considera que los dos órganos que creo la Ley de Autonomía Local (Consejo Andaluz de Gobiernos Locales y el Consejo Andaluz de Concertación Locales) deberían tener una misma legislación no tan dispersa y sí más eficaz, pues los dos órganos dirimen sobre casi los mismos asuntos, con la diferencia que uno de los órganos está conformado íntegramente por entidades locales, mientras que el Consejo Andaluz de Concertación Local se conforma con representantes de la Junta de Andalucía y de la Administración Local.

Considera que tanto la Administración General del Estado como la Administración autonómica tienden al centralismo y a perder las mínimas competencias quedando la Administración Local como una administración permanentemente tutelada.

Plantea sus reservas con respecto al artículo 1 del entonces proyecto de ley así como el hecho que la sede del Consejo Andaluz de Concertación Local esté en Sevilla planteando la necesidad que la sede sea rotatoria. Con respecto al artículo $2^{\circ}$ plantea una mejor definición de los conceptos de coordinación y colaboración..

${ }^{14}$ Los comparecientes en la sesión de la Comisión de Administración Local fueron D. Manuel José Terol Becerra, Catedrático de Derecho Constitucional de la Universidad Pablo de Olavide (Sevilla); D. José Francisco Salado Escaño, Alcalde del Excmo. Ayuntamiento de Rincón de la Victoria; D. José Loaiza García, Presidente de la Excma. Diputación de Cádiz; D. Juan Moreno Rodríguez, Presidente de UCA-UCE; D. José De Casa Martín, Coordinador General de CEPES-A. DSPA num. 335 de 18 de Noviembre de 2014. págs. 3-42. 
En lo que respecta al artículo 3.1 apartado d) plantea la necesidad de que los dictámenes sean vinculantes, sobre todo en lo tocante a modificación de competencias locales.

En relación al artículo 3 que incluye las funciones del Consejo Andaluz de Concertación Local, considera que el listado debería completarse con las referencias a conferir audiencias con relación a las posibles directrices u órdenes internas que afecten a las leyes. Igualmente plantea sobre el artículo 4 la necesidad de suprimir las apelaciones a la definición del consenso.

En relación al artículo 5 que determina la emisión de informes a solicitud del Consejo Andaluz de Gobiernos Locales se establece un quórum reforzado previsto de dos tercios para la emisión del informe del Consejo Andaluz de Concertación Local entiende el compareciente que dicho refuerzo colisiona con el Consejo Andaluz de Gobiernos Locales. Considera que dicho quórum reforzado limita la propia naturaleza de funcionamiento del órgano de colaboración y concertación.

En relación al artículo 6 sobre la composición del Consejo Andaluz de Concertación Local planteando que en lo tocante a la pérdida de condición de miembro del Consejo, pues dicha pérdida de condición no está adaptado a la LOREG. Considera que sería beneficioso que la presidencia fuera rotatoria.

En lo relativo al voto de calidad no debería existir en aras al consenso y sobre todo en el caso del artículo 3.1 apartado d).

El Sr. Salado Escaño considera que se delegan excesivas competencias en la comisión permanente, a la que la nueva Ley se le puede delegar prácticamente todo, al tiempo que pide aumentar el número de reuniones. Pide igualmente que se permita introducir en el orden del día asuntos motivados, veinticuatro horas antes de la reunión.

Se debe añadir un artículo nuevo donde se haga un informe anual de las actuaciones que haya desarrollado el el Consejo Andaluz de Concertación Local, dándose cuenta del mismo al Parlamento de Andalucía.

Con respecto a la composición de la Comisión Permanente, cuando se establece quien es miembro de las entidades locales, se afirma en el texto que será un vocal cuando a juicio del Sr. Salado Escaño debería ser un alto representante de la Federación Andaluza de Municipios y Provincias (FAMP), Considera que no es correcto que el rango que se pone a los representantes de la administración autonómica se fi- 
je en el nivel de una Viceconsejería, mientras que los miembros de la comisión permanente que representan al mundo local tengan rango de vocal. Considera que el texto debe desarrollar con más amplitud la composición de la parte de Gobiernos locales para que haya un reparto equitativo y proporcional entre los distintos municipios por tramo de población, o ver si se incluye a la Diputación, priorizándose además el papel del Consejo Andaluz de Gobiernos locales.

El compareciente Sr. Loaiza García, Presidente de la Excelentísima Diputación de Cádiz indica en su intervención la necesidad de un órgano que defienda las corporaciones locales, planteando que debe potenciarse el Consejo Andaluz de Gobiernos Locales. Un órgano a su juicio, que debe favorecer medidas en favor de la concertación y la colaboración permanente.

Considera que la representación de las corporaciones locales no se puede dejar en manos de una asociación (en este caso la Federación Andaluza de Municipios y Provincias FAMP). Considera que la representación de los miembros de las corporaciones locales debe ser nombrada mediante un sistema de carácter proporcional con arreglo a cómo estén conformados los distintos Gobiernos locales en cada mandato.

Expresa el Sr. Loaiza García que todas las funciones del pleno del Consejo Andaluz de Concertación Local no deben ser delegadas en la Comisión Permanente ya que mientras que los representantes de la Administración autonómica van a cumplir con el mandato del poder ejecutivo andaluz, los representantes de las corporaciones locales pueden tener intereses contrapuestos. Considera que las delegaciones en la Comisión Permanente son excesivas y que debería otorgarse otra redacción a los artículos 3.1.2 y 3.1 apartado d).

Plantea la necesidad de que el futuro Consejo Andaluz de Concertación Local aborde temas relativos a las competencias delegadas o transferidas, así como su correspondiente financiación.

El compareciente Sr. Moreno Rodríguez en nombre de la Unión de Consumidores de Andalucía (UCA-UCE) considera que la norma responde a la necesidad de actualizar lo contenido en el artículo 95 del Estatuto de Autonomía para Andalucía que expresa que una ley debe regular la creación, composición y las funciones o el funcionamiento de un órgano mixto llamado a estar representado por la Junta de Andalucía y por las corporaciones municipales andaluzas. El representante de UCAUCE apuesta por la colaboración institucional a fin de desarrollar una acción colaborativa. A su juicio, el Proyecto de Ley viene a poner orden así como a delimitar las dos figuras preexistentes (el Consejo Andaluz de Gobiernos Locales y el propio Consejo Andaluz de Concertación Local); mientras el primer Consejo estaba llama- 
do a responder al objetivo de instrumentar el diálogo permanente de la concertación y la colaboración, el segundo deberá seguir haciendo efectivo el derecho de participación de las entidades locales en el ámbito de la administración autonómica.

Comparte la previsión planteada y contemplada en el artículo 2.2 relativa a las consultas al Consejo Andaluz de concertación Local y que esta consulta sea preceptiva en los casos previstos en el apartado 1 del artículo 3. Defiende la composición paritaria del órgano tanto en lo relativo a los representantes de la Junta de Andalucía y de las corporaciones locales.

Respecto al artículo 6.2 letra b) en la organización UCA-UCE se genera la duda al hablar de la representación de la persona titular de la presidencia de la FAMP y sobre su consideración de asociación de mayor implantación.

Sobre el artículo 9, relativo a la Comisión Permanente del Consejo Andaluz de Concertación Local deben, a su juicio, delimitarse bien las funciones del pleno y de la Comisión Permanente, para que la comisión permanente no termine suplantando al pleno.

Sobre el artículo 10 relativo a las comisiones de estudio que en su apartado segundo plantea que por acuerdo del Consejo Andaluz de Concertación Local podrán asistir personas expertas, consideran necesario incorporar una alusión expresa a la posible participación de agentes económicos y sociales de relevancia constitucional y estatutaria.

El compareciente Sr. De Casa Martín, Coordinador General de la Confederación Empresarial de la Economía Social de Andalucía (CEPES-A) considera que es necesaria la existencia de un órgano supremo de colaboración y concertación que sea consultado en la tramitación de disposiciones legislativas y planes que afecten de forma específica a las entidades locales y que tenga capacidad para poder formular propuestas al órgano competente relativa a los objetivos, prioridades y financiación de las entidades locales.

Considera que el Consejo Andaluz de Concertación Local debe ser un órgano tripartito con funciones encaminadas al desarrollo local, donde los agentes sociales deben ser tenidos en cuenta en tanto que parte implicada en el desarrollo local. Al mismo tiempo, desde CEPES-A consideran que por su importancia e implantación, las empresas de la economía social deberían estar representadas en el Consejo Andaluz de Concertación Local. 
La réplica a los comparecientes fue establecida por la presidencia de la Comisión ejercida por el Sr. Recio Menéndez (G.P. PSOE-A) en orden de menor a mayor representación de los grupos parlamentarios en la cámara andaluza ${ }^{15}$.

Tras la comparecencia de los distintos agentes sociales, la mesa de la comisión de Administración Local y Relaciones Institucionales del 3 de Diciembre calificó favorablemente y admitió a trámite las enmiendas presentadas al articulado del proyecto de Ley 9-14/PL-000005 por el grupo parlamentario del Partido Popular de Andalucía (G.P. PP-A) y por el grupo parlamentario socialista (G.P. PSOE-A $)^{16}$.

En este sentido las dieciséis enmiendas del G.P. PP-A responden al siguiente contenido:

- Enmienda número 11915 de modificación del párrafo séptimo para establecer la siguiente redacción:

"Por ello, en la presente Ley se adecuan las funciones del Consejo Andaluz de Concertación Local a su naturaleza de órgano de diálogo y colaboración institucional, teniendo en cuenta las que la Ley de Autonomía Local de Andalucía atribuye al Consejo Andaluz de Gobiernos Locales. Asimismo, se produce el reforzamiento de la Comisión Permanente del Consejo, incrementando el número de sus miembros y elevando el rango de su Presidencia".

- Enmienda número 11916 de modificación al artículo 4.1 proponiendo la siguiente redacción:

"4.1:Mediante Decreto del Consejo de Gobierno se aprobará el reglamento por el que se rige la organización, funcionamiento y régimen interior del Consejo Andaluz de Concertación Local, sin perjuicio de que, como órgano colegiado integrado por representantes del Gobierno de la Comunidad Autónoma y de los Gobiernos Locales, pueda establecer normas de funcionamiento que serán aprobadas por mayoría de sus miembros"

- Enmienda número 11917 de supresión del artículo 4.2

- Enmienda número 11918 de modificación del artículo 5.1 proponiéndose la siguiente redacción:

${ }^{15}$ La portavocía del Grupo parlamentario de Izquierda Unida Los Verdes Convocatoria por Andalucía (G.P. IULV-CA) correspondió al Sr. Serrano Jódar; la portavocía del G.P. PSOE-A fue ejercida por el Sr. Carmona Jiménez y la del G.P. PP-A por el Sr. Molina Rascón. Ejerció como Letrado de la Comisión D. Javier Terrón Montero.

${ }^{16}$ Se admiten las enmiendas 11915 a 11932 del G.P. PP-A y la enmienda no 11942 del G.P. PSOE-A. No obstante la calificación favorable, y habiendo sido admitida a tramite la enmienda $\mathrm{n}^{\circ}$ 11942 del G.P. PSOE-A recibió el voto contrario del representante del G.P. PP-A 
"5.1: [...] por resultar afectadas las competencias locales propias, remitirá este pronunciamiento en el plazo máximo de diez días. El citado órgano colegiado podrá solicitar motivadamente el informe del Consejo Andaluz de Concertación Local....".

- Enmienda número 11919 de modificación del artículo 5.2 donde se propone la siguiente redacción:

"5.2: una vez emitido el informe del Consejo Andaluz de Concertación Local se remitirá, según lo dispuesto en el artículo 12 de la presente Ley, al órgano promotor de la iniciativa para su inclusión en el expediente de elaboración de la norma".

- Enmienda número 11920 de modificación del artículo 6.2 epígrafe a) 3a proponiendo la siguiente redacción:

2.a) $3^{a}$ : 2Siete personas vocales designadas por el Consejo de Gobierno de la Funta de Andalucía entre personas titulares de órganos directivos con rango de Viceconsejería, las cuales provendrán de distintas consejerías del Consejo de Gobierno de la Junta de Andalucía de modo que no haya más de dos personas vocales por Consejería".

- Enmienda $n^{\circ} 11921$ de modificación del artículo 7.1 proponiéndose la siguiente redacción:

"7.1: la Presidencia del Consejo Andaluz de Concertación Local se ejercerá por periodos alternos de seis meses por la persona titular de la Consejería competente sobre régimen local y por la persona titular de la Presidencia de la asociación de municipios y provincias de carácter autonómico de mayor implantación".

- Enmienda número 11922 de adición al artículo 7.1, donde se proponía la siguiente redacción:

"7.1bis: De manera excepcional, y previo acuerdo de las partes, la persona titular de la Presidencia de la Junta de Andalucía podrá presidir las reuniones del Pleno del Consejo Andaluz de Concertación Local, según se establezca en el desarrollo reglamentario de los contenido en la presente Ley”.

- Enmienda número 11923 de modificación del artículo 5.1 en la que se planteaba a la siguiente redacción:

“8.1: La Vicepresidencia del Consejo Andaluz de Concertación Local se ejercerá por periodos alternos de seis meses por la persona titular de la Consejería competente sobre régimen local y por la persona titular de la presidencia de la asociación de municipios y provincias de carácter autonómico de mayor implantación". 
- Enmienda número 11924 de modificación del artículo 9.3 b) apartado $1^{\circ}$ proponiéndose la siguiente redacción:

“9.3.b) En representación de los Gobiernos locales:

$1^{\circ}$-la persona titular de la presidencia de la asociación de municipios y provincias de carácter autonómico de mayor implantación a su máximo nivel.

- Enmienda número 11925 de adición al artículo 9.3 para desarrollar la siguiente redacción:

"9.3bis: La comisión Permanente del Consejo Andaluz de Concertación Local se reunirá, al menos una vez al trimestre en sesión ordinaria”.

- Enmienda 11926 de adición al artículo 9 e un nuevo punto (el 4 bis) para aplicar la siguiente redacción:

"9.4bis. Reglamentariamente se establecerán las normas de funcionamiento de la Comisión permanente del Consejo Andaluz de Concertación Local".

- Enmienda número 11927 en la que se plantea la supresión del artículo 9.5

- Enmienda número 11928 de modificación del artículo 11.1 para desarrollar la siguiente redacción:

"11.1: El Consejo andaluz de Concertación Local deberá reunirse, en Pleno, previa convocatoria acordada por la Presidencia, al menos dos veces al año en sesión ordinaria y...."

- Enmienda número 11929 de modificación del artículo 11.3 para aplicar la siguiente redacción:

"11.3: [...] En todo caso será precisa la asistencia de la Presidencia, la Vicepresidencia y de la Secretaría, en su caso, de quienes les sustituyan”.

- Enmienda número 11930 de modificación del artículo 12.1 para desarrollar la siguiente redacción:

"12.1: El plazo para la emisión de los informes y dictámenes del Consejo Andaluz de Concertación Local será de veinte días, salvo que...."

- Enmienda número 11931 de adición de una nueva disposición adicional con la siguiente redacción: 
Disposición Adicional Primera: "En los términos que reglamentariamente se determinen, el Consejo Andaluz de Concertación Local presentará al parlamento de Andalucía un informe anual sobre la actividad desplegada en virtud de las funciones encomendadas".

- Enmienda número 11932 de modificación a la disposición final primera a fin de establecer la siguiente redacción:

Disposición final primera. Desarrollo reglamentario.

"Se autoriza al Consejo de Gobierno de la Junta de Andalucía para dictar, en el plazo máximo de seis meses, cuantas disposiciones sean necesarias para el desarrollo y aplicación de la presente Ley".

Por su parte, el grupo parlamentario socialista (G.P. PSOE-A) presente la enmienda número 11942 donde se propone la adición de una nueva disposición final con la siguiente redacción:

Disposición final - Modificación del apartado 1 de la disposición final quinta de la Ley 1/2014, de 24 de junio de Transparencia Pública de Andalucía.

Se modifica el apartado 1 de la disposición final quinta de la Ley 1/2014, de 24 de junio, de Transparencia Pública de Andalucía, que queda con la siguiente redacción:

1.la presente ley entrará en vigor al año de su publicación en el Boletín oficial de la funta de Andalucía, salvo lo dispuesto en su Título V, que entrará en vigor el 1 de enero de 2015”.

En la sesión de la Comisión de Administración Local y Relaciones Institucionales celebrada el 10 de Diciembre de 2014 se procedió al debate y votación del dictamen de la Comisión relativo al Proyecto de Ley 9-14/PL-000005 ${ }^{17}$.

En dicha comisión ejercieron como portavoces D. Juan Serrano Jódar (G.P. IULV-CA), D. Manuel Carmona Jiménez (G.P. PSOE-A) y D. Antonio Sanz Cabello (G.P. PP-A).

Planteadas las enmiendas del Grupo parlamentario popular y del Grupo socialista, las enmiendas del G.P. PP-A éstas fueron rechazadas por siete votos a favor, 8 votos en contra y ninguna abstención.

${ }^{17}$ DSPA num. 351 de 10 de diciembre de 2014. Págs. 2-13 
En relación a la votación del Dictamen, éste fue aprobado por 8 votos a favor, ningún voto en contra y 7 abstenciones.

En relación al posicionamiento de los grupos parlamentarios, que intervinieron ordenados de menor a mayor por tiempo de diez minutos, el Diputado Sr. Serrano Jódar que posicionó el voto contrario del grupo parlamentario de IULV-CA a las enmiendas presentadas por el G.P. PP-A en lo relativo a las modificaciones propuestas al artículo 17.3 de la Ley 5/2010 de 11 de junio; al artículo 4.1 planteando que el contenido de la enmienda propuesta por el grupo parlamentario popular tendría mejor acomodo en una disposición final si bien el contenido de la enmienda a su juicio se incluye ya en la disposición primera que especifica el régimen jurídico aplicable al órgano.

Considera igualmente que la aprobación de la norma de funcionamiento del órgano, debe efectuarse por consenso y no por mayoría de votos afirmativos como propone el G.P. PP-A, al ser el régimen general establecido para la adopción de sus acuerdos.

Expone la posición contraria de su grupo a la enmienda al artículo 4.2 presentada por el G.P. PP-A. En relación a la enmienda que afecta al artículo 5.1 que pretende establecer un plazo de diez días para que el órgano proponente se pronuncie sobre las observaciones o reparos del Consejo Andaluz de Gobiernos Locales,considera, en primer lugar, que este aspecto no debe ser objeto de esta norma, ni tan siquiera de regulaciones posteriores, sino que esta adecuación debe entenderse en el marco del procedimiento de elaboración de disposiciones de carácter general, en el que el órgano promotor debe valorar todas las observaciones formuladas y comunicar su posición. Considera que la enmienda planteada por el G.P. PP-A puede crear disfunciones e interferir en los distintos trámites previstos en los mismos. En este sentido el portavoz del G.P. IULV-CA no comparte la necesidad de establecer dicho plazo.

El G.P. IULV-CA votó en contra de la enmienda que afecta al artículo 5.2 al considerar que el informe al que refiere el citado artículo, en el ejercicio de la función prevista en el artículo 3.1.b) presenta una serie de peculiaridades al tratarse de una suerte de segunda instancia que aconseja reitera el plazo previsto con carácter general para la emisión de informes y dictámenes del Consejo.

En la enmienda relativa al artículo 12, el G.P. IULV-CA considera que la expresión propuesta no hace referencia precisa al plazo, sino a la forma y procedimiento de emisión que no se regula en dicho artículo.

En relación a la enmienda del G.P. PP-A que afecta al artículo 6.2 a), el G.P. IULV-CA vota en contra al rechazar que se haga referencia expresa a que no puedan existir más de dos vocales por Consejería, puesto que los nombramientos deben efectuarse en función de las competencias sobre la materia. 
El portavoz del G.P. IULV-CA Sr. Serrano Jódar expresa la posición contraria a la enmienda del grupo popular que afecta al artículo 7.1 al considerar que la alternativa propuesta para un ejercicio de la Presidencia del Consejo con carácter semestral a compartir entre la persona titular de la Consejería competente y la persona que ejerza la presidencia de la Federación Andaluza de Municipios y Provincias (FAMP) generaría inestabilidad en el funcionamiento del órgano.

En relación al artículo 7.1bis el G.P. IULV-CA no considera necesaria la enmienda pues no es adecuado incluir la previsión que, de manera excepcional, y previo acuerdo de las partes y desarrollo reglamentario, la Presidencia de la Junta de Andalucía pueda presidir las reuniones del Consejo Andaluz de Concertación Local.

Sobre la enmienda del G.P. PP-A que afecta al artículo 9.3 b) apartado $1^{\circ}$, el G.P IULV-CA no asumió la propuesta de concretar la representación de los Gobiernos Locales en la Comisión Permanente del Consejo.

Sobre la enmienda al artículo 9.3bis el G.P IULV-CA no aceptó la propuesta ya que el artículo 11 prevé la periodicidad de las reuniones que con carácter ordinario, sesionará al menos una vez al año.

En relación a la enmienda al artículo 9.4bis el GP.IULV-CA no la aceptó al no suponer una mejora técnica del texto.

Sobre la enmienda del G.P. PP-A que afecta al artículo 11.3 el G.P. IULV-CA planteó una transaccional al grupo proponente.

En lo relativo a los plazos establecidos, se plantea no aceptar la enmienda del G.P. PP-A al artículo 12.1.

El G.P. IULV-CA si aceptó la enmienda sobre la adición de una nueva disposición adicional.

La enmienda relativa a la modificación de la disposición adicional primera no es aceptada por el G.P. IULV-CA

Por su parte el G.P. PSOE-A plantea su posición contraria a las enmiendas del G.P. PP-A que afectan a la exposición de motivos del Proyecto de Ley; la relativa al artículo 4.1 ; la que afecta al artículo 5.1 y 5.2 así como la que afecta al artículo 6.2 a). El G.P. PSOE-A plantea su rechazo a las enmiendas del G.P. PP-A que afectan a los artículos 7.1, 7.1bis, artículo 9.3 b) apartado 1: Dicha posición contraria se hace extensiva a los artículos 9.3bis, 9.4bis y 9.5 
La enmienda del G.P. PP-A que afecta a la redacción del artículo 11.1 si fue aceptada mientras se rechazó la enmienda que afecta al artículo 11.3 y al artículo 12.1.

Finalmente el G.P. PSOE-A aceptó la enmienda relativa a la Disposición adicional mientras se rechaza la enmienda que afecta a la Disposición adicional $1^{\text {a }}$.

El grupo proponente del mayor número de enmiendas, planteó en su intervención que de las dieciocho enmiendas planteadas, doce eran de modificación, dos de supresión y cuatro de adición. Todas la enmiendas pretendían no reforzar la preeminencia de la Junta de Andalucía frente a los Gobiernos Locales en el Consejo Andaluz de Concertación Local.

El G.P. PP-A plantea la necesidad de modificar el concepto de consenso planteando que los siete vocales designados por el Consejo de Gobierno de la Junta de Andalucía deben representar a distintas consejerías debido al carácter interdisciplinar del municipalismo, poniendo en valor a la FAMP.

El G.P. PP-A reitera su voluntad de aumentar la presencia del mundo local dentro del Consejo, elevar la dimensión del Consejo mediante una presidencia semestral y rotatoria que pudiera ser ocupada por la persona titular de la Presidencia de la Junta de Andalucía.

\section{IV.- DEBATE FINAL DEL PROYECTO DE LEY 9-14/PL-000005 DEL CONSEJO ANDALUZ DE CONGERTACIÓN LOGAL EN LA SESION PLENARIA DEL PARLAMENTO DE ANDA- LUCÍA DE 22 DE DICIEMBRE DE 2014.}

Las intervenciones de los grupos parlamentarios ordenados de menor a mayor comienzan por el G.P. IULV-CA, su portavoz Sr. Serrano Jódar expresa que el Estatuto de Autonomía para Andalucía mandara realizar una ley que regule la creación, la composición y funcionamiento de un órgano mixto, con representación de la Junta de Andalucía y de los Ayuntamientos andaluces, para funcionar como órgano permanente de diálogo y colaboración institucional para una correcta gestión. Considera que el Proyecto de Ley incide en la mejora de la transparencia y la comunicación. Desde IULV-CA plantean su apoyo a todas las reformas que refuercen las funciones de las entidades locales, otorgándole a los municipios plena decisión sobre como organizar y gobernar los territorios ${ }^{18}$.

${ }^{18}$ DSPA num.102 de 22 de diciembre de 2014. Págs. 2-18 
El G.P. IULV-CA considera que la Administración más cercana debe ser la que tenga más capacidad de tomar decisiones que le afecten, dotando de suficientes recursos económicos para la consecución eficiente de sus políticas, seguridad financiera para un mayor bienestar social y garantías de servicios públicos de calidad.

Desde IULV-CA defienden un modelo de Gobiernos locales de proximidad, adaptables a las singularidades del mapa local andaluz. Un modelo que desarrolle y potencie la autonomía local y las competencias con recursos suficientes para hacerlas efectivas.

Apuestan por un municipalismo que pueda reconocerse en la Carta Europea de la Autonomía Local que indica que las entidades locales deben ser consultadas en la medida de sus posibilidades en todas aquellas cuestiones que les afecten directamente y que se relacionen con los principios de simplificación, transparencia y modernización de los entes locales; el principio de autonomía; diferenciación, equilibrio territorial, desarrollo sostenible y suficiencia financiera, así como el derecho a participar de forma eficaz y directa en los asuntos públicos.

La Ley del Consejo Andaluz de Concertación Local, como Ley para la creación de un órgano mixto con representación de la Junta de Andalucía y los municipios andaluces viene a sustituir y renovar los contenidos de la Ley aprobada en 2007 y que sirvió para crear el órgano consultivo para la colaboración institucional y el diálogo entre las entidades locales y la Junta de Andalucía. El G.P. IULV-CA considera que el Consejo Andaluz de Concertación Local hará efectivo el derecho de representación y participación de los municipios en las decisiones autonómicas junto a la búsqueda de instrumentos de cooperación eficaces para el logro de medidas o finalidades que se pretendan desarrollar.

El G.P. PSOE-A a través de su portavoz, Sr. Carmona Jiménez considera que con la aprobación de la Ley del Consejo Andaluz de Concertación Local por el Parlamento de Andalucía se da cumplimiento al mandato estatutario y a lo dispuesto en el artículo 4 de la Carta Europea de la Autonomía Local. Se culmina así el proceso de elaboración de una norma que viene a perfeccionar e institucionalizar las modalidades de participación y decisión de las entidades locales en las cuestiones de índole legislativa que versen sobre temas que les incumban directamente.

La propia exposición de motivos del Proyecto de Ley realiza un repaso de los antecedentes de este órgano, que fue creado por la Ley 20/2007 en cumplimiento de los dispuesto por el artículo 95 del Estatuto de Autonomía para Andalucía.

Así, cuando la Ley 5/2010 de 11 de junio de Autonomía Local de Andalucía crea el Consejo Andaluz de Gobiernos locales como órgano de representación unitaria de 
los municipios y como garante de las competencias locales se hizo necesario precisar y delimitar el papel de ambos órganos. La propia Ley de Autonomía Local derivó competencias del Consejo Andaluz de Concertación Local al Consejo Andaluz de Gobiernos Locales en aras del cumplimiento de los principios de descentralización y una mayor autonomía local. Reservaba la Ley de Autonomía Local al Consejo Andaluz de Concertación Local el papel de órgano supremo de colaboración e instrumento de diálogo y concertación entre la unta de Andalucía y las corporaciones locales.

El G.P. PSOE-A considera que con esta nueva norma se adecua el Consejo Andaluz de Concertación Local a sus funciones y naturaleza de órgano de diálogo, se articula un nuevo régimen de adopción de acuerdos, minorando el carácter dirimente del voto del Presidente. Se refuerza la comisión permanente y se establece un régimen específico para la resolución de problemas de interpretación y cumplimiento en los procesos sobre transferencia de competencias.

Las funciones del Consejo Andaluz de Concertación Local quedan definitivamente enumeradas en el artículo 3.1, que no ha sido objeto de enmiendas durante el proceso y que son las siguientes:

- Ser consultado en la tramitación parlamentaria de las disposiciones legislativas y planes que afecten a las entidades locales.

- Informar de anteproyectos de Ley, proyectos de disposiciones generales y propuestas de planes si el proponente rechaza observaciones o reparos del Consejo de Gobiernos Locales en temas de su competencia.

- Formular propuestas de transferencia o delegación de competencias.

- Resolver problemas de interpretación y cumplimiento en el proceso de transferencia previsto en el artículo 16.3 de la Ley de Autonomía Local, así como cualquier tipo de traslación competencial o incluso reversión.

- Realizar propuestas relativas a objetivos, prioridades y financiación de las corporaciones locales.

- Emitir parecer en procedimientos sobre creación, supresión o alteración de términos municipales así como en los cambios de nombre o capitalidad de los municipios.

- Formular a la Consejería de Administración Local, propuestas de colaboración con las provincias.

- Formular propuestas de de cooperación con las corporaciones locales ante el órgano competente de la Junta de Andalucía para la consecución de los fines de asistencia a los que se refiere el artículo 60 de la Ley de Autonomía Local.

- Recibir información sobre los casos de disolución de las Corporaciones Locales por gestión gravemente dañosa.

- Cualquiera otra que le pueda ser atribuida por Ley. 
Así, el Consejo se configura como un órgano de concertación y no de confrontación. El protagonismo y el respeto a la autonomía de la Federación Andaluza de Municipios y Provincias (FAMP) queda intacto. El carácter dirimente del voto del Presidente del Consejo Andaluz de Concertación Local queda atenuado en el marco de un Consejo Andaluz de Gobiernos Locales que asume más competencias.

El G.P. PSOE-A valora positivamente la nueva norma, considerando que hay un nutrido grupo de enmiendas aceptadas que se han incorporado al articulado. En este sentido el portavoz del G.P. PSOE-A, Sr. Carmona Jiménez anunció el apoyo de su grupo a la Ley del Consejo Andaluz de Concertación Local.

Reitera finalmente las dos principales conclusiones otorgadas en el debate de totalidad; la Junta de Andalucía sitúa a los Ayuntamientos como sujetos activos en la gestión de sus políticas y por ende mantiene su carácter de Comunidad Autónoma marcadamente avanzada en materia de autonomía local.

Finalmente, el G.P. PP-A a través de su portavoz, la Sra. Mestre García, indica que el Partido Popular cree en la coordinación con las entidades locales, si bien no cree en el uso que realiza el Gobierno andaluz de este tipo de órganos ni del uso que realiza de la palabra "consenso".

Plantea que ha faltado consenso a la hora de afrontar el debate sobre las 16 enmiendas presentadas por su grupo y que afectaban a tres bloques conceptuales:

- Enmiendas en pro del equilibrio participativo.

- Enmiendas en pro de la operatividad y la utilidad.

- Enmiendas en pro de la coordinación de las partes en tanto que órgano mixto.

El Partido Popular, en palabras de su portavoz Sra. Mestre García que gobierna el $65 \%$ de la población andaluza no quiere hablar desde la demagogia, sino desde el interés general de crear órganos útiles que nada tengan que ver con el partidismo.

La portavoz del G.P. PP-A critica que la única enmienda que aporta el G.P. PSOE-A sea una enmienda que afecta a una modificación del Título V de la Ley de Transparencia de Andalucía, al tiempo que considera que el Proyecto de Ley del Consejo Andaluz de Concertación Local minimiza el municipalismo.

Como cierre a las intervenciones de los grupos parlamentarios, el Presidente del parlamento de Andalucía, Sr. Gracia Navarro concede la palabra al Vicepresidente de la Junta de Andalucía y Consejero de Administración Local y Relaciones Institucionales, Sr. Valderas Sosa a fin de concluir el debate en nombre del Consejo de Gobierno. 
El Sr. Valderas Sosa considera que la Ley del Consejo Andaluz de Concertación Local es una Ley oportuna que viene a contribuir al desarrollo de los principios de concertación, diálogo y codecisión con el mundo local. Se cumple así con lo dispuesto en el artículo 57 de la Ley 5/2010 de 11 de junio de Autonomía Local. Entiende además, que la Ley ha sido mejorada en su tramitación parlamentaria.

Continua afirmando que, a partir de la aprobación de la Ley refuerza las funciones locales y avanza en el reconocimiento del papel del municipalismo, la lealtad institucional y la coordinación entre administraciones.

Una vez sustanciado el debate se sometieron a votación las enmiendas presentadas por el G.P. PP-A que fueron rechazadas al obtener 59 votos en contra, 45 votos a favor y ninguna abstención.

A continuación se sometió a votación el dictamen de la Comisión de Administración Local y Relaciones Institucionales relativo al Proyecto de Ley del Consejo Andaluz de Concertación Local, que resultó aprobado por 59 votos a favor, ningún voto en contra y 45 abstenciones, quedando definitivamente aprobada la Ley 9/2014 del Consejo Andaluz de Concertación Local siendo publicada en el Boletín Oficial de la Junta de Andalucía del 31 de diciembre de 2014.

\section{BIBLIOGRAFÍA Y FUENTES.}

ARAGÓN REYES, M.: "El tratamiento constitucional de la autonomía local” en Organización territorial del Estado, Instituto de Estudios Fiscales, Madrid, 1985.

AJA, Elíseo: "Configuración constitucional de la autonomía municipal", en Informe sobre el Gobierno Local, MAP, Madrid, 1992.

ALONSO MAS, M.J. : "La protección de la autonomía local frente a normas con valor de ley" en Nuevas perspectivas de régimen local. Estudios en homenaje del profesor José María Boquera Oliver (Baño León; Climent Barberá, coords.), Tirant Lo Blanch, Valencia, 2002.

BALLESTEROS FERNÁNDEZ, A.: Manual de Administración Local (4 $4^{\mathrm{a}}$ Ed.), Editorial Comares, Granada, 1998.

BARNÉS VÁZQUEZ, J.: "Descentralización y desconcentración en Andalucía” en DA, 214, 1988.

-"Subsidiariedad y autonomía local en la Constitución" en Anuario del Gobierno Local 1997, Diputación de Bacelona-Marcial Pons, Madrid, 1997. 
-"Un Estado de autonomía y una Constitución del Siglo XX" en Revista de Administración Pública, num, 173, Madrid, Mayo-Agosto, 2007.

CAAMAÑO DOMÍNGUEZ, F. (Coord.): La autonomía de los entes locales en positivo. La carta Europea de la Autonomía Local como fundamento de la suficiencia financiera, Fundación democracia y Gobierno Local, Madrid, 2003.

GAlOngE, A.; GARCÍA, J.A.; GONZÁLEZ, T. : Descentralización y coordinación de competencias, Universidad de Valladolid, 1995.

CRUZ VILLALÓN, P.: "La reforma del Estado de las autonomías" en Revista d'Estudis Autonòmics i Federals, num. 2, 2006.

ENDEMAÑO AROSTEGUI, J.M. :'Las competencias municipales en la legislación de régimen local" en RVAP, 58, 2000.

ESTEVE PARDO, J. . "Garantía constitucional y la función constitucional en las bases de régimen local" en Revista de Estudios Derecho Constitucional, num. 31, 1991.

FANLO LORAS, A. . Fundamentos constitucionales de la autonomía local, Centro de Estudios Constitucionales, Madrid, 1990.

FONT i LLOVET, T. : "El recurso de protección constitucional de la autonomía local" en Defensa de la Autonomía local ante el Tribunal Constitucional, INAP, Madrid, 1997, págs. 89 y ss.

-"El Gobierno local en la reforma del Estado de las Autonomías" en Anuario del Gobierno Local 2004, 2005.

-"Órganos consultivos" en Revista de Administración Pública, num. 108, 1985.

-"El régimen local en la reforma de los Estatutos de autonomía" en El régimen local en la reforma de los estatutos de autonomía, Centro de Estudios Políticos y Constitucionales, Madrid, 2006.

GALÁN GALÁN, A.: "Naturaleza de la Ley de régimen local de Andalucía y su relación con las leyes autonómicas sectoriales" en Anuario del Gobierno Local, Institut de Dret Public, Barcelona, 2009.

GARCíA FERNÁNDEZ, J. : "La autonomía del Derecho Político municipal. Fundamentos dogmáticos en la Constitución Española" en Organización territorial del estado (Administración Local), Instituto de Estudios Fiscales, Madrid, 1985.

GARCÍA ROCA, J. : "El concepto actual de autonomía local según el bloque de la constitucionalidad", en Revista de estudios de la Administración Local y Autonómica, 282, 2000. 
GARCÍA FERNÁNDEZ, J. : "Derecho constitucional y entidades locales. Sistema de fuentes y autonomía como fundamentos constitucionales básicos de la autonomía local", en Parlamento y Constitución, num, 6, 2002.

GÓMEZ MONTORO, A. : "La garantía constitucional de autonomía local” en Repertorio Aranzadi de Jurisprudencia Constitucional, num. 1, 1999.

JIMÉNEZ CAMPO, J. : "Notas sobre la protección de la autonomía local frente al legislador en el Derecho español" en Revista Española de Derecho Constitucional , num. 53, 1998.

JIMÉNEZ SÁNCHEZ, G.: "Configuración constitucional y tutela de la autonomía local” en Revista Andaluza de Administración Pública, num. 51, 2003.

LÓPEZ GUERRA, L.: "La función constitucional y el contenido del Estatuto de Autónomía" en Estudios sobre la reforma del Estatuto, Institut d'Estudis Autonomics $i$ Federals, 2004.

LÓPEZ-MEDEL BÁSCONES, J.: “Autonomía y descentralización local”, El Consultor de los Ayuntamientos y los fuzgados, Madrid, 2003.

MÁRQUEZ CRUZ, G.: "Gobierno local y pacto local” en REGAP, num. 25, 2000.

MARTÍN MATEO, R. : "La garantía constitucional de las autonomías locales" en Revista de estudios de la vida local, num 28, 1980.

MEDINA ALCOZ, L. : La participación de los entes locales en la elaboración de normas autonómicas y locales, Madrid, INAP, 2009.

MEDINA GUERRERO, M. : "Hacia una participación eficaz de los entes locales en la toma de decisiones de la Comunidad Autónoma, ¿Del Consejo andaluz de Concertación Local al Consejo de Gobiernos Locales? Revista CEMCI. Num. 8, Julio- septiembre 2010.

-"Crónica parlamentaria. El debate final de la Ley de Autonomía Local en Andalucía" en Revista Andaluza de Administración Pública, num. 76, 2010.

MIR i BAGÓ, J. : El sistema español de competencias locales, Marcial Pons, Madrid, 1991.

MORELL OGAÑA, L. : La Administración Local, Tecnos, Madrid, 1984.

ORTEGA ÁLVAREZ, L. : "La carta Europea de la Autonomía local y el ordenamiento español" en Revista de Estudios de la Administración Local y Autonómica, num. 259, 1993. 
ORTIZ MONTORO, R.J. : "Comentarios al proyecto de Ley de Autonomía Local de Andalucía de 2009" en El Consultor de los Ayuntamientos y los Juzgados, num. 5, quincena 15-29 de marzo, 2009.

ORTIZ DÍAZ, J.: Principios jurídicos de la organización administrativa, Universidad de Sevilla, 1990.

PAREJO ALFONSO, J.: Garantía constitucional y autonomías locales, Instituto de estudios de Administración Local, Madrid, 1981.

-Derecho básico de la Administración Local, Ariel, Barcelona, 1988.

-"La protección jurídica de la autonomía local en el derecho español" en Defensa de la autonomía local ante el tribunal Constitucional, INAP, Madrid, 1997.

-"La autonomía local en la Constitución" Tratado de Derecho municipal, Tomo I, segunda edición, Civitas, Madrid, 2003.

PORRAS RAMÍREZ, J.: El conflicto en defensa de la autonomía local ante el Tribunal Constitucional, Civitas, Madrid, 2001.

- Las reformas estatutarias y el nuevo sistema autonómico de fuentes del Derecho, Civitas, Madrid, 2007.

REQUEJO PAGÉS, J.L.: "Garantía de la autonomía local y Estatutos de Autonomía" en Anuario del Gobierno Local, 2006.

RIVERO YSERN, J.L. : Manual de Derecho Local, Civitas, Madrid, 1997.

RODRÍGUEZ ÁLVAREZ, J.M. : "La Carta Europea de la autonomía local. Su trascendencia y significación en el ordenamiento jurídico español" en Actualidad administrativa, num. 42, Noviembre de 1997.

RUIZ-RICO RUIZ, G.: La forma de Gobierno en Andalucía, Tirant Lo Blanch, Valencia, 2009.

RUIZ ROBLEDO, A.: El ordenamiento jurídico andaluz, Civitas, Madrid, 1991.

SÁNCHEZ ISAC, J. : El principio de autonomía y las competencias locales, Bayer hermanos, Barcelona, 2002.

SÁNCHEZ MORÓN, M. . : La autonomía local, Givitas, Madrid, 1992.

SOSA WAGNER, F.: Manual de Derecho Local, Aranzadi, Navarra, 2002. 
TEROL BECERRA, M.J.: El Estado autonómico in fieri; la reforma de los estatutos de Autonomía, Instituto Andaluz de Administración Pública, Sevilla, 2005.

TOSCANO GIL, F.; VILLALTA REIXACH, M. : "El consejo Andaluz de Concertación Local; una oportunidad perdida para la autonomía local en Andalucía" en Revista Andaluza de Administración Pública. Num. 70, 2008.

TUDELA ARANDA, J.: Derechos constitucionales y autonomía política, Civitas, Madrid, 1994.

VELASCO CABALLERO, F.: "Autonomía local en los nuevos Estatutos de autonomía”. Ponencia en las jornadas Reforma del Gobierno Local en Andalucía, CEMCIFundación Democracia y Gobierno Local. Granada, 18 y 19 de enero de 2010.

VILLALTA REIXACH, M.: "nuevas formas de participación de los entes locales; el Consejo de Gobiernos Locales" en Revista d'Estudis Autonòmics i Federals, num. 2, 2006.

-’El Consejo de Gobiernos locales. La nueva participación de los entes locales en las CG.AA.", Madrid, IUSTEL, 2007.

ZAFRA VÍCTOR, M. : "Autonomía local. Un pilar en la articulación del Estado de las Autonomías" en Relaciones Institucionales entre CC.AA. y Gobiernos Locales, Sevilla, Instituto Andaluz de Administración Pública, 2008.

-"Gobernanza local" en Gómez Torralbo, Estado del Bienestar y Gobernanza, Sevilla, Instituto Andaluz de Administración Pública, 2007. 